\title{
PARTISIPASI MASYARAKAT DALAM MENDUKUNG DESA WISATA EKOLOGIS DI DESA NYAMBU, KECAMATAN KEDIRI, KABUPATEN TABANAN
}

\author{
${ }^{1}$ Putu Agus Suantara, \\ ${ }^{2}$ Ir. Ida Bagus Made Parsa, MM, \\ ${ }^{3}$ NGA.Diah Ambarwati Kardinal, ST.,MT \\ Program Studi Perencanaan Wilayah dan Kota \\ Fakultas Teknik \\ Universitas Hindu Indonesia
}

\begin{abstract}
Nyambu Village is a Tourism Village that takes the ecological concept (Ecotourism), The beauty of natural scenery and culture makes Nyambu Village has the attraction to be visited by tourists. Nyambu village atmosphere with all its contents is the perfect big potential with the unification of nature and culture which is the strong character of Nyambu Village itself. This study describes how community participation in supporting Ecological Tourism Village in Nyambu Village, Kediri Sub-district, Tabanan District, and describes the form of community participation, the level of community participation in planning, implementation, utilization, evaluation, business opportunity and identifying factors influence public participation through age, sex, education and employment. This research is a qualitative research using deductive approach, with data collection methods obtained from field observation, interview and secondary data from related offices while interviews and questionnaires conducted by the method of puposive sampling. There are four forms of participation in Nyambu Village, among others, the participation of money, the participation of material or matter, the participation of personnel, the participation of the mind, and the level of participation in the planning, implementation, utilization, evaluation and business opportunities are very good. while the involvement or participation of Nyambu Village community on village tourism activities that took place in Nyambu Village Kediri District, Tabanan Regency seen from the factor of participation is the age factor of 17-28 years old with high school education.
\end{abstract}

Keywords: Tourism Village, Ecotourism, Community Participation, Forms of community participation, Level of community participation Facto-factors that influence participation.

\section{Pendahuluan}

Pengembangan desa wisata pada saat ini berkembang sangat pesat, terutama di pulau bali yang di kenal sebagai destinasi wisata dunia. Ketertarikan wisatawan terhadap budaya lokal yang di sajikan oleh masyarakat menjadi daya tarik sendiri dan berhasilnya pembangunan nasional sebagai pengamalan pancasila, tergantung pada partisipasi seluruh rakyat Indonesia serta sikap mental, tekad semangat ketaatan disiplin para penyelenggaran Negara serta seluruh rakyat Indonesia.

Berdasar Undang-Undang Otonomi Daerah (UU.No.22/99) yang diberlakukan mulai tahun 2000, yang sekarang mengalami perubahan menjadi Undang-undang No. 32 Tahun 2004 tentang otonomi daerah, maka terjadi pergeeresan dalam pembangunan ekonomi yang awalnya sentralis menjadi desentralisasi, yaitu dengan memberikan keleluasaan kepada daerah untuk membangun wilayahnya termasuk pembangunan dalam bidang ekonominya. Dengan adanya otonomi daerah yang di tetapkan oleh pemerintah pusat maka pemerintah daerah dapat membangun ekonomi daerah sesuai dengan potensi yang dimilikinya. Potensi tersebut bisa dijadikan untuk meningkatkan ekonomi masyarakat dan pemasukan daerah. Seprti halnya jika suatu daerah mempunyai tempat wisata yang berpotensi untuk dikomersialkan maka pemerintah harus memberikan perhatian khusu pada tempat tersebut dan masyarakatnya. Masyarakat dihimbau untuk melestarikan dan pemerintah juga membantu mempromosikan lokasi tersebut untuk dapat dikunjungi para wisatawan. Jika tempat wisata itu akan maju maka masyarakat didaerah tersebut akan lebih mendapatkan dampaknya seprti dapat berjualan, menyediakan penginapan, dan juga di bidang jasa lainnya. difokuskan di daerah pedesaan. Dengan demikian akan terjadi perubahan sosial kemasyarakatan dari urbanisasi ke ruralisasi (orang-orang kota senang/akan pergi ke desa untuk berekreasi). Departemen Pariwisata telah membuat program yang disebut pola PIR (Pariwisata Inti Rakyat), dengan mengembangkan pembangunan desa wisata. Dengan dikembangkannya pembangunan desa wisata akan terjadi arus urbansiasi ke ruralisasi yang selama ini terjadi karena pembangunan lebih banyak terjadi di daerah perkotaan, sehingga orang-orang desa banyak pergi ke kota untuk mencari pekerjaan, dan kemudian menetap di kota.

Desa Nyambu Kecamatan Kediri ditetapkan sebagai salah satu desa wisata 
Partisipasi Masyarakat Dalam Mendukung Desa Wisata Ekologis Di Desa Nyambu, Kecamatan Kediri, Kabupaten Tabanan

sebagaimana tertuang dalam pasal 51 RTRWK Tabanan No. 11 Tahun 2012. Desa Nyambu Kecamatan Kediri sebagai model Desa Wisata Ekologis ( DWE ) yang memiliki potensi pariwisata, alam dan budaya, usaha pariwisata yang dikembangkan oleh masyarakat seperti, Industri ukiran Kayu, pande Besi, Olahan Pangan dan Sanggah. Villa yang tersebar diseluruh banjar kecuali banjar carik padang, Seni budaya: barong bangkung, tari rejang, tari masenau, topeng pajegan, topeng sidakarya, barong ket, rangda, rejang rentet, tari leko, sesolahan pinggel. Peluang pengembangan wisata ekologis, pariwisata ekologis adalah perjalanan ketempat tempat alami yang relatif masih belum terganggu atau terkontaminasi (tercemari) dengan tujuan untuk mempelajari, mengagumi dan menikmati pemandangan, tumbuh-tumbuhan dan satwa liar, serta bentukbentuk manifestasi budaya masyarakat yang ada, baik dari masa lampau maupun masa kini."

Desa Wisata Ekologis Nyambu merupakan salah satu model pengembangan kapasitas masyarakat dalam mengelola usaha pariwisata untuk meningkatkan pendapatan masyarakat melalui pengenalan potensi desa, kekayaan alam, seni budaya yang nantinya dapat dikelola langsung oleh masyarakat desa setempat. Melalui kegiatan Nyambu EcoTourism masyarakat diharapkan dapat kembali mendalami sejarah dan tatanan budaya desa yang mereka yakini secara turun temurun. Desa Nyambu disamping memiliki potensi alam seperti sawah dan mata air, desa ini juga memiliki peninggalan sejarah yang mewariskan jejak peradaban panjang masyarakat Bali, mulai jaman Bali Kuno, era Majapahit hingga saat ini.

Ada beberapa pura yang tersebar di masing-masing banjar dinas. Dalam kigiatan Desa Wisata Nyambu dimana bentuk partisipasi uang berupa peminjaman modal dalam pengembangan desa wisata, bentuk paertisipasi pikiran berupa ide dan gagasan dalam pengembangan desa wisata, bentuk partisipasi tedaga dalam hal pelaksanaan, bentuk partisipasi materi dan benda dalam hal pengetahuan dan alat-alan oprasional. Sedangkan tingkan partisipasi masyarakat Desa Wisata Nyambu dalam perencanaan, pelaksanaan pemanfaatan, evaluasi, pemanfaatan peluag kegiatan usaha sestra faktor apa saja yang mempengeruhi partisipasi masyarakat seperti umur, jenis kelamin, pendidikan, pekerjaan. Berpijak pada permasalahan diatas serta untuk menjaga keseimbangan antara kegiatan pembangunan dengan kegiatan pelestarian serta aspek-aspek kehidupan lainnya pada Kawasan Desa Wisata Nyambu.
Luas wilayah Desa Nyambu adalah 348 Ha. Secara geografis dan administratif, wilayah Desa Nyambu berbatasan dengan :

Sebelah Utara : berbatasan dengan Desa Abiantuwung

Sebelah Timur : berbatasan dengan Desa Tukad Yeh Ulam

Sebelah Selatan : berbatasan dengan Desa Buwit

Sebelah Barat : berbatasan dengan Desa Tukad Yeh Sungi

Secara geografis Desa Nyambu berada pada posisi $8^{0} 33^{\prime} 44^{\prime \prime}-8^{0} 35^{\prime} 36^{\prime \prime} \mathrm{LS}, 115^{\circ}$ 07'50'- $115^{0} 18^{\prime}$ 'BT. Desa Nyambu merupakan wilayah yang sangat subur, terdapat 22 mata air atau pancoran. Desa Dinas Nyamu meliputi 6 (enam) dusun/banjar, dapat di lihat dari tabel berikit: Br. Carik, Br. Nyambu, Br. Tohjiwa, Br. Mundeh, Br. Kebayan dan Br. Dukuh.

\section{Metode Penelitian}

Jenis penelitian ini adalah penelitian kualitatif, dengan menggunakan pendekatan bersifat deduktif Menurut Bungin (2007) dalam Umbara (2014:47), model pendekatan deduktif merupakan model yang masih menjadikan teori sebagai alat dalam penelitian sejak memilih dan menemukan masalah, maupun melakukan pengamatan di lapangan. Metode deduktif yang digunakan adalah metode deduktif kualitatif. Metode deduktif kualitatif merupakan prosedur penelitian yang menghasilkan data deskriptif berupa kata-kata tertulis atau lisan dari orang/ obyek yang diamati Yunus (2010:23). Dengan menggunakan metode deduktif kualitatif, hasil dari penelitian ini nantinya berupa gambaran detail dari suatu masalah/ subyek tertentu.

Pendekatan penelitian ini digunakan untuk memecahkan atau menjawab permasalahan yang sedang dihadapi pada situasi sekarang. Teori yang digunakan dalam penelitian ini yaitu teori tentang desa wisata, desa wisata ekologis serta teori partisipasi masyarakat. Inti dari penelitian ini terfokus pada partisipasi masyarakat dalam mendukung Desa Wisata Ekologis Nyambu. Pembahasan dalam penelitian ini dilakukan secara deskriptif, yaitu menemukan pengetahuan seluas-luasnya terhadap objek penelitian pada suatu saat tertentu dengan cara menjelaskan atau membuat deskripsi secara terstruktur. Menjelaskan keadaan empiris lapangan dan menguji teori atau hipotesis yang didasarkan pada data kualitatif. Data kualitatif yang akan dianalisis berupa hasil wawancara narasumber terkait di lapangan yang kemudian akan dianalisis secara deskrptif.

Setelah ditetapkan sebagai Desa Wisata masyarakat Desa Nyambu mulai merubah pola hidup manjadi lebih peka terhadap lingkungan 
sekitar dimana Keindahan panorama alam dan budaya, menjadikan Desa Nyambu memiliki daya tarik tersendiri bagi wisatawan. Suasana Desa Nyambu dengan seluruh isinya adalah potensi besar yang sempurna dengan menyatunya alam dan budaya yang merupakan karakter kuat dari Desa Nyambu. Dukungan masyarakat dalam aktivitas Desa wisata Ekologis Nyambu antara lain dengan selalu menerapkan kesadaran dan pemahaman apa sebenarnya Desa Wisata Ekologis itu, apa manfaat yang diperoleh dari pengembangan Desa Wisata Ekologis itu antara lain adalah alam yang terjaga dengan baik dan kesadaran masyarakat tentang lingkungan sehingga lestarinya budaya setempat.

Wisata yang dilaksanakan di Desa Nyambu sendiri adalah wisata alam dan budaya, dimana ditambah dengan susur sungai dan bersepeda. Penyelenggaraan wisata Alam dan Budaya di Desa Wisata Ekologis tidak terlepas dari partisipasi masyarakatnya, karena masyarakat merupakan motor penggerak dari kegiatan Desa Wisata Nyambu itu sendiri. Nymbu Ecotourism bersama dengan Perbekel Desa Nyambu, Tokoh masyarakat, Kelian Dinas dan STT Se-Desa Nyambu yang terdiri dari 6 banjar berkerja sama dengan British Council dan Yayasan Wisnu lembaga swadaya masyarakat (LSM) yang aktif menggagas dan menjalankan program ekowisata di Bali.

Nyambu Ecotourism merupakan salah satu pengelolaan Desa Wisata Ekologis Di Desa Nyambu Kediri Tabanan yang melibatkan Partisipasi masyarakat secara langsung, yang dimana masyarakat ikut mengelola desa wisata sebagai penyedia akomodasi home stay, pemandu wisata lokal, galeri lukisan dan pemetaan potensi desa.

Kemajuan Desa Wisata Ekologis di Desa Nyambu Kecamatan Kediri, tidak terlepas dari adanya kerjasama yang baik antara Pemerintah Desa Nyambu dengan Pengelola Ecotourism dan lembaga adat yang ada, yaitu Desa Pakraman, serta masyarakat yang ada di Desa Nyambu. Kondisi tersebut ditambah dengan potensi alam seperti mata air dan purapura yang memiliki sejrah yang sangat menarik, merupakan modal utama bagi masyarakat Desa Nyambu sehingga pengembangan potensi desa wisata yang terdapat di wilayahnya secara maksimal, yang secara tidak langsung telah memberikan dampak positif bagi perkembangan wisataan di Kabupaten Tabanan, bahkan di Bali pada umumnya.
Banyak upaya yang dilaksanakan oleh masyarakat Desa Nyambu dalam rangka melestarikan potensi alam dan budaya yang dimilikinya. sekaligus guna menarik kunjungan wisatawan yang datang ke Desa Wisata Nyambu.

Salah satu upaya yang dilaksanakan di bawah koordinasi lembaga Desa dan pengelola Nyambu Ecotourism, yaitu dengan mengadakan secara rutin pertemuan antara tokoh masyarakat, STT Se- Desa Nyambu yang mengambil tempat di kantor perbekel Desa Nyambu. Di samping itu juga melalui media sosial seperti Facebook, Instagram. Desa Wisata Nyambu mulai ingin di kenal sebagai Desa Wisata Ekologis demi upaya menumbuh kembangkan partisipasi masyarakat terutama pada generasi muda terhadap potensi alam dan budaya yang di miliki oleh Desa Nyambu. Sehingga regenerasi terhadap konservasi alam dan budaya dapat berjalan sesuai harapan masyarakat Desa Nyambu yang mememang memfokuskan diri sebagai desa yang berkiblat di wisata ekologis untuk menjaga kelestarian alam dan budaya setempat.

Selanjutnya, sebagai salah satu ajang promosi Desa Wisata Ekologis Nyambu, masyarakat Desa Nyambu, secara rutin mempromosikan potensi desa melalui media sosial Facebook, Instagram dan pada saat ini pemerintah desa bersama pengelola Nyambu Ecotourism merencanakan Kegiatan-kegiatan yang bertujuan untuk mendukung Program Desa Wisata Ekologis Nyambu seperti Nyambu Bersepeda. Kegiatan Nyambu Bersepeda rencananya akan segera diadakan pada tanggal 18 april 2018, oleh Pemerintah Desa dan Nyambu Ecotourism untuk menampilkan potensi alam dan budaya melalui bersepeda menyusuri Desa Nyambu agar Desa Wisata Ekologis Nyambu lebih di kenal oleh wisatawan.

\section{Hasil dan Pembahasan}

\section{Partisipasi Uang}

Dalam mendukung kegiatan Desa Wisata Ekologis Nyambu bentuk partisipasi uang untuk memperlancar usaha-usaha masyarakat yang memerlukan bantuan untuk kegiatan usaha di danai melalui badan usaha milik desa ( BUMDES ) yang dimana masyarakat di arahkan oleh pemerintah desa membentuk kelompok dengan anggota sekitar 10-15 Orang yang di fokuskan di sektor pemerdayaan perempuan (PKK Desa Nyambu). 
Partisipasi Masyarakat Dalam Mendukung Desa Wisata Ekologis Di Desa Nyambu, Kecamatan Kediri, Kabupaten Tabanan

\section{Partisipasi Materi dan Benda}

Partisipasi dalam bentuk materi dan benda untuk di Desa Wisata Ekologis Nyambu menurut pengamatan wawancara dan observasi lapangan, menyumbang materi dalam arti pengetahuan maupun benda, lebih dominan dari pihak lain seperti Yayasan Wisnu dan British Council, yang dimana partisipasi dalam bentuk materi disediakan oleh pihak luar seperti pelatihan untuk pemandu wisata loakal, pelatiahn dalam mempersiapkan kamar untuk tamau menginap, pelatihan memasak, pembuatan vidio. Dan benda berupa alat-alat kerja juga di fasilitasi oleh pemerintah desa dan pihak dari Yayasan Wisanu. Hal ini di pertegas oleh Perbekel Desa Nyambu dan pengelola Nyambu Ecotourism.

Partisipasi Tenaga

Partisipasi yang diberikan dalam bentuk tenaga dalam pelaksanaan usaha-usaha yang dapat menunjang keberhasilan suatu program yang di gagas oleh pengelola dan pemeritah desa dalam kegiatan Desa Wisata Nyambu sangatlah besar.

\section{Partisipasi Pikiran}

Partisipasi berupa sumbangan ide, pendapat, baik untuk menyusun program Desa Wisata Nyambu maupun untuk memperlancar pelaksanaan program dan juga untuk mewujudkannya dengan memberikan pengalaman dan pengetahuan guna mengembangkan kegiatan yang akan di programkan di Desa Wisata Ekologis Nyambu

\section{Tingkat Partisipasi Masyarakat Desa Wisata Nyambu}

Tingkatan partisipasi merupakan derajat keterlibatan masyarakat dalam sebuah program terlihat dari kesempatan masyarakat untuk terlibat dan mempengaruhi jalannya program. Dimana tingkat partisipasi masyarakat pada tahap perencanaan berada pada tingkat Partisipasi sumu sebesar 58\%, tingkat partisipasi masyarakat pada tahap pelaksanaan berada pada tingkat kekuatan masyarakat sebesar 53\%, tingkat partisipasi masyarakat pada tahap pemanfaatan berada pada tingkat kekuatan masyarakat sebesar $70 \%$, tingkat partisipasi masyarakat pada tahap evaluasi berada pada tingkat partisipasi semu sebesar $72 \%$ dan tingkat partisipasi masyarakat pada tahap kegiatan peluang usaha berada pada tingkat kekuata masyarakat dan partisipasi semu sebesar 50\%$50 \%$.

Faktor Usia
Usia berpengaruh pada keaktifan seseorang untuk berpartisipasi dalam kegiatan Mendukung Desa Wisata Ekologis Nyambu hal ini dapat di lihat dari partisipasi pemuda Se-Desa Nyambu dan yang tergabung sebagai pengelola desa wisata ialah dari usia 17-28 tahun.

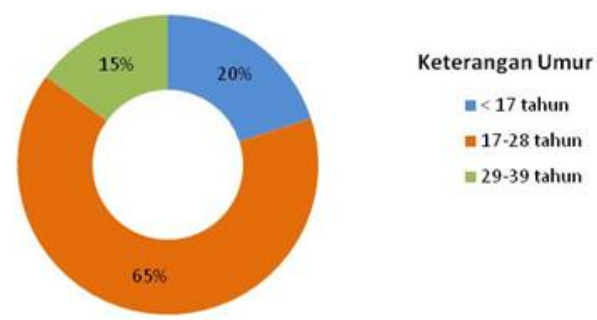

Gambar 1 Presentase Responden Berdasarkan Faktor Usia

Sumber : Hasil Kuisioner, diolah 2018

\section{Faktor Jenis kelamin}

Laki - laki dan perempuan memiliki peran yang sama dalam mendukung Desa Wisata Ekologis Nyambu terlihat dari pelibatan PKK Desa Nyambu yang berpartisipasi dalam kegiatan wisata sebagai penyiapan konsumsi bagi wisatawan dan Truni Desa Nyambu yang sebagai pemandu wisata lokal dalam kegiatan Desa Wisata Nyambu dan pemuda Se-Desa Nyambu.

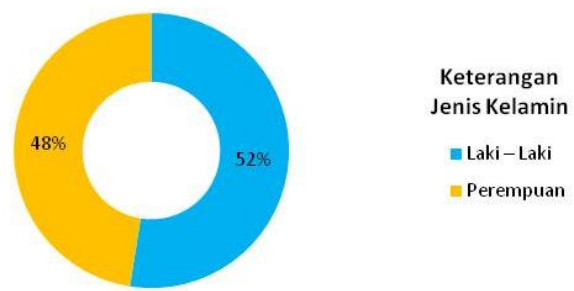

\section{Gambar 2 Presentase Responden Berdasarkan} Faktor Jenis kelamin

Sumber : Hasil Kuisioner, diolah 2018

\section{Faktor Pendidikan}

Tingkat partisipasinya dalam pembangunan khususnya partisipasinya dalam bentuk mendukung Desa Wisata Ekologis Nyambu, faktor pedidikan yang paling berperan adalah pada tingkat SMA.

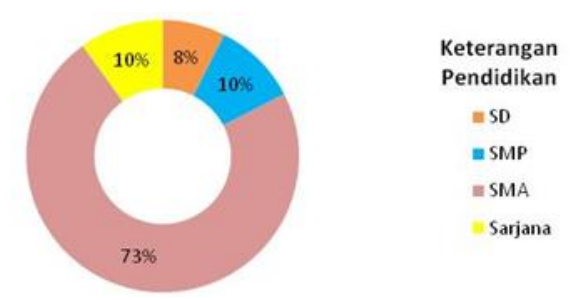

Gambar 3 Presentase Responden Berdasarkan Faktor Tingkat Pendidikan

Sumber : Hasil Kuisioner, diolah 2018 


\section{Faktor Pekerjaan}

Untuk faktor pekerjaan, di Desa Nyambu kebanyakan yang berpartisipasi adalah pemuda Desa Nyambu yang tidak secara langsung sebagai pengelola. Sedangkan aparat desa dan kelian dinas yang memang memiliki pekerjaan tetap di desa sebagai pengelola Desa Wisata Ekologis yang tergabung di dalam Nyambu Ecotourism.

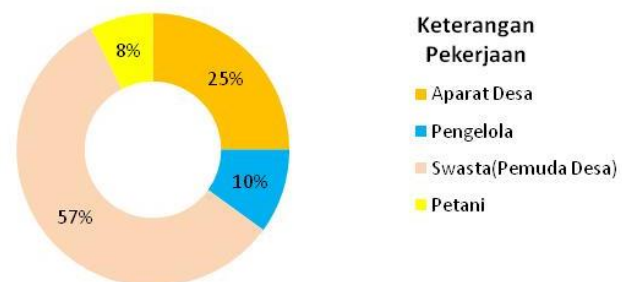

Gambar 4 Presentase Responden Berdasarkan Faktor Menurut Pekerjaan

Sumber : Hasil Kuisioner, diolah 2018

\section{Kesimpulan dan Saran}

\section{Kesimpulan}

Empat Bentuk partisipasi masyarakat yang di jabarkan oleh Keith Davis yang dilakukan oleh masyarakat lokal meliputi partisipasi uang dimana masyarakat Desa Nyambu yang ingin mengembangkan usaha dalam mendukung Desa Wisata Nyambu di dukung penuh oleh Aparat Desa Nyambu yang pendanaannya melalui BUMDES (Badan Usaha Milik Desa). Partisipasi materi yang terdapat di Desa Nyambu berupa materi pengetahuan seperti pelatihan pemandu wisata lokal. Partisipasi alat-alat untuk menunjang kegiatan Desa Wisata Nyambu bentuknya kamera untuk kegiatan dokumentasi dan itu pun melalui yayasan wisnu. Bentuk partisipasi tenaga yang terdapat di Desa Nyambu berupa kegiatan pemetaan potensi desa dan bentuk partisipasi pikiran yang terdapat di Desa Nyambu berupa ide dan gagasan untuk mendukung perkembangan Desa Wisata Ekologis Nyambu.

Tingkat partisipasi masyarakat Desa Nyambu dalam mendukung kegiatan Desa Wisata Ekologis yang mengacu pada perencanaan, pelaksanaan, pemanfaatan, evaluasi dan pemanfaatan peluang usaha, dapat di simpulkan sangat baik. Hal ini dikarenakan Kekuatan Masyarakat dengan indikator (kemitraan, delegasi, kendali warga) dan Partisipasi Semu dengan indikator (informasi, konsultasi, penentraman) dalam mendukung Desa wisata Nyambu sangat baik dan seimbang tidak saling tumpang tindih.

Faktor - faktor yang mempengaruhi partisipasi masyarakat dalam pengembangan Desa Wisata Nyambu Kecamatan Kediri,
Kabupaten Tabanan dimana Usia 17-28 Tahun merupakan usia yang paling dominan dibandingkan dari usia kurang dari 17 tahun

Berdasarkan jenis kelamin, maka partisipasi masyarakat hampir sama dikarenakan antara laki-laki dan perempuan memiliki kekuatan yang sama dalam kegiatan Desa Wisata Nyambu. Faktor Pendidikan mengacu pada faktor usia dimana pemuda Se-Desa Nyambu yang berpartisipasi dalam mendukung Desa Wisata adalah anak muda yang berpendidikan SMA (Sekolah Menengah Atas). Faktor pekerjaan sebagai aparat desa dan pengelola desa wisata tidak mempengaruhi faktor tingkat partisipasi masyarakat Desa Nyambu, melainkan yang memiliki persentase tertinggi adalah pemuda desa yang memilikin pekerjaan tetap diluar sebagai pengelola Desa Wisata Nyambu Ecotourism.

\section{Saran}

Bagi Pemerintah Daerah (Provinsi Bali dan Kabupaten Tabanan) dan pihak terkait Ekowisata dapat memberikan pendampingan kepada Aparat Desa Nyambu dan pengelola Nyambu Ecotourism dalam peningkatan skill masyarakat di bidang manejemen wisata dalam mendukung Desa Wisata Ekologis Nyambu agar terbentuknya partisipasi masyarakat dalam menjaga lingkungan, alam, dan budaya mereka sendiri.

Kepada masyarakat Desa Nyambu hedaknya dapat meningkatkan partisipasi masyarakat dalam pengelolaan potensi wisata yang tersedia di lokasi Desa Wisata Nyambu karena masyarakat adalah komponen yang paling utama, serta untuk aparat pemerintahan desa agar semakin aktif dalam hal pemerdayaan masyarakat, agar masyarakat Desa Nyambu partisipasinya meningkat di dalam mendukug Desa Wisata Ekologis Nyambu.

\section{DaftarPustaka}

Buku

Saryono, dkk.2010. Metodologi Penelitian Kualitatif. Yogyakarta: Nuha Media

Sastropoetro, Santoso R.A. 1988. Partisipasi, Komunilasi, Persuasi, dan Disiplin Dalam Pembangunan Nasional. Bandung: Alumni.

Siti Irene Astuti Dwiningrum. 2011. Desentralisasi dan Partisipasi Masyarakat Dalam Pendidikan.Yogyakarta: Pustaka Pelajar. 
Partisipasi Masyarakat Dalam Mendukung Desa Wisata Ekologis Di Desa Nyambu, Kecamatan Kediri, Kabupaten Tabanan

\section{Peraturan}

Peraturan Bupati tentang RTBL Desa Wisata Nyambu, KediriKabupaten Tabanan Provinsi Bali pasal 51 RTRWK Tabanan No. 11 Tahun 2012.DesaNyambuKecamatan Kediri sebagai model Desa Wisata Ekologis ( DWE)

RTBL Desa Nyambu.

Jurnal ilmiah

Cahya, Andri Tri, dkk. 2017. Partisipasi Masyarakat Dalam Pengembangan Atraksi Wisata Air Terjun Kampung Anyar, Kabupaten Banyuwangi.

http://administrasibisnis.studentjou rnal.ub.ac.id/index.php/jab/article/ view/1671. 16 Januari 2018

Dewi, Made Heny Urmila, dkk. 2013. Pengembangan Desa Wisata Berbasis Partisipasi Masyarakat Lokal Di Desa Wisata Jatiluwih Tabanan,

Bali.https://jurnal.ugm.ac.id/kawist ara/article/view/3976. 17 Januari 2018

Suroso, Hadi, dkk. 2014. Faktor-Faktor Yang Mempengaruhi Partisipasi Masyarakat Dalam Perencanaan Pembangunan di Desa Banjaran Kecamatan Driyorejo Kabupaten Gresik. https://media.neliti.com/media/pub lications/40087-ID-faktor-faktoryang-mempengaruhi-partisipasimasyarakat-dlam-perencanaanpembang.pdf. 20 Januari 2018

Lutpi, Hakkiatul. 2016. Analisis Tingkat Partisipasi Masyarakat Dalam Pengembangan Pariwisata Pantai Di Kecamatan Jerowaru. https://ejournal.undiksha.ac.id/inde x.php/JJPE/article/download/8695/ 5661. 17 Januari 2018.

Tugas akhir/tesis

Ishak, Fistarisma. 2016. Analisis Partisipasi Masyarakat Dalam Menunjang Pembangunan Desa di Kecamatan Tongauna Kabupaten Konawe [Skripsi]. Kendari. Jurusan Ilmu Ekonomi, Fakultas Ekonomi dan Bisnis, Universitas Halu Oleo.
Sapei, Abdulah. 2015. Partisipasi Masyarakat Dalam Program Pengembangan Desa Pesisir Tangguh di Kecamatan Teluknaga Kabupaten Tangerang [Skripsi]. Serang. Fakultas Ilmu Sosial Ilmu Politik, Universitas Ageng Tirtayasa.

Suryawan, A.Adib. 2004. Studi Partisipasi Masyarakat Dalam Pelestarian dan Pengembangan Kawasan Alun - alun Surakarta. Pendidikan Program Sarjana Jurusan Teknik Perencanaan Wilayah dan Kota. Universitas Diponegoro. Semarang

\section{Publikasi elektronik}

Saca Firmansyah. 2009 Partisipasi Masyarakat. Diakses pada 17 Januari 2018 dari http://sacafirmansyah.wordpress.com/2009/06/0 5/partisipasi-masyarakat. 